\title{
A Quantitative Analysis of Tariffs across U.S. States *
}

\author{
Ana Maria Santacreu ${ }^{\dagger} \quad$ Michael Sposi ${ }^{\ddagger} \quad$ Jing Zhang ${ }^{\S}$ \\ October 2018 \\ Preliminary and incomplete. Please do not circulate.
}

\begin{abstract}
We build a multisector general equilibrium model of trade to quantify the effect of U.S. tariffs both at the national and global level. The model incorporates regionspecific input-output linkages, endogenous capital accumulation and endogenous trade imbalances. We estimate sector-specific bilateral trade frictions and productivity levels for 50 U.S. states and 41 non-U.S. countries across 2 sectors of the economy using detailed bilateral trade and production data. We then simulate welfare Laffer curves for each state by varying the U.S. tariff rate. We consider two cases: (i) No retaliation from the foreign countries and (ii) Tit-for-Tat retaliation. We find that the tariff rate that maximizes consumption varies across states and it ranges from $14 \%$ to $45 \%$ when there is no retaliation and from $0 \%$ to $13 \%$ when there is retaliation. Furthermore, we find that these tariffs correlate negatively with the ratio of foreign exports to GDP.

Keywords: International trade, input-output linkages, state-level trade, optimal tariffs JEL Classifications: F11, F62
\end{abstract}

\section{Introduction}

We build a multisector general equilibrium model of trade to quantify the effect of U.S. tariffs both at the national and global level. The model features input-output linkages, endogenous

*The views in this paper are those of the authors and do not necessarily reflect the views of the Federal Reserve Banks of Dallas, St. Louis, Chicago or the Federal Reserve System.

${ }^{\dagger}$ Federal Reserve Bank of St. Louis, P.O. Box 442, St. Louis, MO 63166. am.santacreu@gmail.com

†Southern Methodist University and Federal Reserve Bank of Dallas. msposi@smu.edu

$\S$ Federal Reserve Bank of Chicago, 230 South LaSalle Street, Chicago, Illinois 60604-1413. jzhangzn@gmail.com 
capital accumulation, and endogenous trade imbalances. We model heterogeneity both across countries and across U.S. states in terms of their sectoral composition, economic ties with foreign countries and geography.

We use bilateral trade data between 50 U.S. states and 41 non-U.S. countries (including rest-of-world aggregate) and 2 sectors (goods and services). We use gravity to infer bilateral trade costs and productivity in these sectors. We also use gravity to impute missing services trade flows.

We look at regional variation in the gains from trade within the United States. Aggregating data to the United States implies that certain types of interactions between states within the United States is invariant to trade policy. However, there is potentially enough heterogenity between U.S. states to make the responses to changes in tariffs to be asymmetric. This asymmetry can further induce changes in trade flows across U.S. states, therefore attenuating the effect of tariffs on the aggregate. On the other hand, by disaggregation, we are acknowledging frictions between U.S. states that are assumed away with aggregation. So the response of the U.S. as a whole is a quantitative question. Nonetheless, the heterogeneity across U.S. states in response to trade shocks is interesting enough in itself to warrant investigation.

We use heterogeneity across U.S. states to characterize the optimal national tariff rate preferred by each state. Specifically, we vary the U.S. tariff rate and trace out Laffer curves that describe the welfare for each state. Each states Laffer curve implies a different optimal tariff rate, which correlates negatively with the ratio of foreign exports to GDP.

\section{Model}

Regions are indexed by $(n, i)=1, \ldots, N$, sectors by $(j, k)=1, \ldots, J$, and time by $t=$ $1, \ldots, T$. Each region admits a representative household that owns the raw factors of production: capital and labor. Capital and labor are mobile across sectors but are immobile across regions. Households can trade one-period bonds. Factor income is spent of consumption and investment and net-foreign income on NFAs is spent on consumption, investment, and net-purchases on bonds. There is no uncertainty in the model and households have perfect foresight.

Endowments The representative household in country $n$ is endowed with population $L_{n}$, which is constant over time. Each period the household decides the total labor supply, 
$H_{n t}$. In period 1 the household in country $n$ is endowed with an initial stock of capital, $K_{n 1}$, and an initial net foreign asset (NFA) position, $\mathcal{A}_{n 1}$. These stocks evolve endogenously throughout time based on investment and saving decisions.

Technology There is a unit interval of potentially tradable varieties in each sector indexed by $v^{j} \in[0,1]$ for $j=1, \ldots, J$.

Within each sector, region $n$ bundles all of the varieties with constant elasticity in order to construct a sectoral composite good according to

$$
Q_{n t}^{j}=\left[\int_{0}^{1} Q_{n t}^{j}\left(v^{j}\right)^{1-1 / \eta} d v^{j}\right]^{\eta /(\eta-1)},
$$

where $\eta$ is the elasticity of substitution between any two varieties. The term $Q_{n t}^{j}\left(v^{j}\right)$ is the quantity of variety $v^{j}$ used by country $n$ at time $t$, which can be either imported or purchased domestically, to construct the sector $j$ composite good. The composite good, $Q_{n t}^{j}$, is allocated for domestic use as either an intermediate input or for final consumption or final investment.

Each variety can be produced using capital, labor, and composite goods. The technologies for producing each variety in each sector are given by

$$
Y_{n t}^{j}\left(v^{j}\right)=z_{n}^{j}\left(v^{j}\right)\left(A_{n}^{j} K_{n t}^{j}\left(v^{j}\right)^{\alpha} H_{n t}^{j}\left(v^{j}\right)^{1-\alpha}\right)^{\nu_{n}^{j}}\left(\prod_{k=1}^{J} M_{n t}^{j k}\left(v^{j}\right)^{\mu_{n}^{j k}}\right)^{1-\nu_{n}^{j}} .
$$

The term $M_{n t}^{j k}\left(v^{j}\right)$ denotes the quantity of the composite good of type $k$ used by country $n$ to produce $y_{n t}^{j}\left(v^{j}\right)$ units of variety $v^{j}$ in sector $j$ at time $t . K_{n t}^{j}\left(v^{j}\right)$ denotes the amount of capital stock used, $H_{n t}^{j}\left(v^{j}\right)$ denotes the amount of workers employed .

The country-specific parameter $\nu_{n}^{j} \in[0,1]$ is the share of value added in total output in sector $j$, while $\mu_{n}^{j k} \in[0,1]$ is the share of composite good $k$ in total spending on intermediates by producers in sector $j$, with $\sum_{k} \mu_{n}^{j k}=1$. The term $\alpha$ denotes capital's share in value added, which is constant across sectors and across countries. All of these parameters are constant over time.

The term $A_{n}^{j}$ is the fundamental productivity, which scales value-added, of all varieties in sector $j$ of country $n$. The term $z_{n}^{j}\left(v^{j}\right)$ scales gross-output of variety $v^{j}$ in sector $j$ of country $n$. Following Eaton and Kortum (2002), gross-output productivities in sector $j$ for each variety are drawn independently from a Fréchet distribution with sector-specific shape 
parameter $\theta^{j}$. The c.d.f. for idiosyncratic productivity draws in sector $b$ in country $i$ is $F^{j}(z)=\exp \left(-z^{-\theta^{j}}\right)$.

Preferences The representative household's preferences are defined over consumption per capita, $\left\{C_{n t} / L_{n}\right\}_{t=1}^{T}$, and labor supply per capita, $\left\{H_{n t} / L_{n}\right\}_{t=1}^{T}$ :

$$
\mathcal{U}_{n}=\sum_{t=1}^{T} \beta^{t-1} L_{n} u\left(\frac{C_{n t}}{L_{n}}, \frac{H_{n t}}{L_{n}}\right) .
$$

Utility between adjacent periods is discounted by $\beta \in(0,1)$. The period-utility function is given by

$$
u\left(\frac{C_{n t}}{L_{n}}, \frac{H_{n t}}{L_{n}}\right)=\ln \left(\frac{C_{n t}}{L_{n}}\right)+\zeta_{n} \frac{\left(1-\frac{H_{n t}}{L_{n}}\right)^{1-1 / \phi}}{1-1 / \phi} .
$$

The term $\phi$ captures the elasticity of labor supply with respect to the real wage, which constant across countries and over time. The term $\zeta_{n}$ represents the utility derived from leisure, relative to that derived from consumption-' 'labor wedge" - in country $n$.

Consumption in country $n$ at time $t, C_{n t}$, bundles the consumption of composite goods from all sectors according to

$$
C_{n t}=\prod_{j=1}^{J}\left(C_{n t}^{j}\right)^{\omega_{n}^{c j}}
$$

where $C_{n t}^{j}$ denotes consumption of the sector $j$ composite good by country $n$ at time $t$ and $\omega_{n}^{c j}$ denotes sector $j$ 's weight in the country $n$ 's consumption bundle (i.e., $\sum_{j=1}^{J} \omega_{n}^{c j}=1$ ).

Capital accumulation Each period the representative household enters the period with $K_{n t}$ units of capital. A fraction $\delta$ depreciates during the period while gross capital formation (investment), denoted by $X_{n t}$, adds to the stock of capital subject to an adjustment cost. The stock of capital is then carried over into the next period. Thus, with $K_{n 1}>0$ given, the capital accumulation technology is

$$
K_{n t+1}=(1-\delta) K_{n t}+\chi X_{n t}^{\lambda} K_{n t}^{1-\lambda}
$$

The term $\chi$ reflects the marginal efficiency of investment, and $\lambda$ is the elasticity of capital accumulation with respect to investment.

Investment in country $n$ at time $t, X_{n t}$, bundles the investment of composite goods from 
all sectors according to

$$
X_{n t}=\prod_{j=1}^{J}\left(X_{n t}^{j}\right)^{\omega_{n}^{x j}}
$$

where $X_{n t}^{j}$ denotes investment of the sector $j$ composite good by country $n$ at time $t$ and $\omega_{n}^{x j}$ denotes sector $j$ 's weight in the country $n$ 's investment bundle (i.e., $\sum_{j=1}^{J} \omega_{n}^{x j}=1$ ).

Net-foreign asset accumulation Each period the representative household enters the period with a net-foreign asset (NFA) position $\mathcal{A}_{n t}$. If $\mathcal{A}_{n t}>0$ then country $i$ has, on net, a positive balance at time $t$, and a debt position otherwise. The NFA asset position is augmented by net purchases of one-period bonds, $B_{n t}$, the current account balance. Thus, with $\mathcal{A}_{n 1}$ given, the NFA position evolves according to

$$
\mathcal{A}_{n t+1}=\mathcal{A}_{n t}+B_{n t}
$$

The household is forced to exit the model with a NFA position $\mathcal{A}_{n T+1}$, which is determined outside of the model.

Household constraints The household purchases consumption and investment at the prices $P_{c i t}$ and $P_{x i t}$, respectively. Income is earned by supplying capital and labor. The household can borrow or lend to the rest of the world by trading one-period bonds, where $B_{i t}$ denotes the value of the net purchases of bonds. The world interest rate on one-period bonds at time $t$ is denoted by $q_{t}$. If the household has a positive NFA position at time $t$, then net foreign income, $q_{t} \mathcal{A}_{i t}$, is positive. Otherwise net foreign income is negatve as resources go to pay off existing liabilities. The period budget constraint is given by

$$
\sum_{j=1}^{J}\left(P_{n t}^{j} C_{n t}^{j}+P_{n t}^{j} X_{n t}^{j}\right)+B_{n t}=r_{n t} K_{n t}+w_{n t} H_{n t}+q_{t} \mathcal{A}_{n t}
$$

We impose that labor supply must be nonnegative and no greater than the size of the population.

$$
H_{n t} \in\left[0, L_{n}\right]
$$

Lastly, consumption and investment in each sector must be non-negative, but these constraints will never bind due to Inada conditions. 
Trade International trade is subject to barriers. Country $n$ must purchase $d_{n i}^{j} \geq 1$ units of any variety of sector $j$ from country $i$ in order for one unit to arrive; $d_{n i}^{j}-1$ units melt away in transit. As a normalization, $d_{n n}^{j}=1$ for all $(n, j)$.

Equilibrium A competitive equilibrium satisfies the following conditions: i) taking prices as given, the representative household in each country maximizes its lifetime utility subject to its budget constraint and technologies for accumulating physical capital and assets, ii) taking prices as given, firms maximize profits subject to the available technologies, iii) intermediate varieties are purchased from their lowest-cost provider subject to the trade barriers, and iv) markets clear. At each point in time, world GDP is defined as the numéraire: $\sum_{n=1}^{N} r_{n t} K_{n t}+w_{n t} H_{n t}=1$. That is, all prices are expressed in units of current world GDP.

One remark is in order here. Since the world interest rate is strictly nominal, the value plays essentially no role other than pinning down a numéraire. That is, in the model the prices are reported in terms of current units of world GDP. In other words, the model can be rewritten so that all prices are quoted in constant (time-1) prices (i.e., an Arrow-Debreu world), which would correspond to a world interest rate of zero in every period. Such a model yields identical quantities in equilibrium. Working with current-price units rather than constant-price units allows for an easier mapping between model and data. Each equilibrium condition is described in the Appendix.

\section{Calibration}

The calibration exercise is applied 91 regions: 50 U.S. states, 40 non-U.S. countries, and a rest-of world aggregate. Economic activity is split across 20 sectors of the economy: (1) Agriculture; (2) Mining; (3) Food, beverages, and tobacco; (4) Textiles and apparel; (5) Wood, paper, and printing; (6) Refined petroleum; (7) Chemical, plastic, and rubber; (8) Processed metal; (9) Machinery and equipment; (10) Furniture and other; (11) Construction; (12) Wholesale and retail trade; (13) Transport and warehouse; (14) Arts, entertainment, recreation, accommodation, and food services; (15) Information; (16) Finance, insurance, and real estate; (17) Professional and business services; (18) Educational services; (19) Health care; (20) Other services.

The primary data sources include Bureau of Economic Analysis Regional Economic Accounts (BEA), Census Bureau Commodity Flow Survey (CFS), Census Bureau Foreign Trade Database (FTB), version 9.0 of the Penn World Table (Feenstra, Inklaar, and Timmer, 2015, 
(PWT)), World Input-Output Database (Timmer, Dietzenbacher, Los, Stehrer, and de Vries, 2015; Timmer, Los, Stehrer, and de Vries, 2016, (WIOD)), and Centre d'Etudes Prospectives et d'Informations Internationales (CEPII).

All of the targets for the calibration are based on data for the year 2012. This choice is restricted by the available information on bilateral trade between U.S. states provided by Census Bureau's Commodity Flow Survey, for which 2012 is the most recent available. For the remainder of this section, time subscripts are omitted to ease notation.

\subsection{Common parameters}

The elasticity of substitution between varieties in the composite goods is set to $\eta=2$. This value plays no quantitative role other than satisfying, which holds in our model. Capital's share in value added is set to $\alpha=0.33$ in line with Gollin (2002).

The rate of depreciation for capital is set to $\delta=0.06$. The elasticity of capital accumulation with respect to investment, $\lambda$, is set to 0.55 based on Eaton, Kortum, Neiman, and Romalis (2016). The marginal efficiency of investment is set to $\chi=\delta^{1-\lambda}$ so that there are no adjustments costs in the steady state (i.e., $X_{n}=\delta K_{n}$ ).

We assign values for sectoral trade elasticities in agriculture (sector 1 in our classification), mining (sector 2 in our classification), and the 8 manufacturing sectors (sectors 3-10 in our classification) using estimates in Caliendo and Parro (2015). There are no estimates for the trade elasticities in service sectors to our knowledge. However, Sposi (2016) constructs an estimate of 6.2 for the trade elasticity for the service sector as a whole; we set $\theta^{j}=6.2$ for each of the 10 service sectors (sectors 11-20 in our classification).

The period discount factor is set to $\beta=0.96$ to be consistent with a steady-state annual real interest rate of roughly 4 percent. We set Frisch elasticity of labor supply, $\phi=2$ based on Peterman (2016).

\subsection{Country-specific parameters}

Some of the country-specific parameters are directly observable, while others need to be inferred using structural relationships implied by the model.

Endowments Population data, $L_{n}$ are read directly from the data. At the country level the data are taken from PWT. At the U.S. state level, the data are taken from Census. 
Table 1: Common parameters

\begin{tabular}{llc}
\hline \hline Technology parameters & & \\
Elasticity of substitution b/w varieties in composite goods & $\eta$ & 2 \\
Capital's share in value added & $\alpha$ & 0.33 \\
Depreciation rate for capital & $\delta$ & 0.06 \\
Marginal efficiency of investment & $\chi$ & 0.28 \\
Elasticity of capital accumulation w.r.t. investment & $\lambda$ & 0.55 \\
Preference parameters & & \\
Discount factor & $\beta$ & 0.96 \\
Elasticity of labor supply & $\phi$ & 2 \\
Trade elasticities & & \\
Agriculture & $\theta^{1}$ & 8.1 \\
Mining & $\theta^{2}$ & 15.7 \\
Food, beverages, and tobacco & $\theta^{3}$ & 2.6 \\
Textiles and apparel & $\theta^{4}$ & 5.6 \\
Wood, paper, and printing & $\theta^{5}$ & 10.0 \\
Refined petroleum & $\theta^{6}$ & 51.1 \\
Chemical, plastic, and rubber & $\theta^{7}$ & 3.1 \\
Processed metal & $\theta^{8}$ & 6.2 \\
Machinery and equipment & $\theta^{9}$ & 6.1 \\
Furniture and other & $\theta^{10}$ & 5.0 \\
Each service sector & $\theta^{11}-\theta^{20}$ & 6.2 \\
\hline
\end{tabular}

The U.S. state level populations are scaled proportionately so that the sum across U.S. states equal the U.S. population in PWT.

Region $n$ 's initial NFA, $\mathcal{A}_{n 1}$, is chosen so that, in steady state, the trade deficit is financed by net-foreign income: $F_{n}=q \mathcal{A}_{n}$. The world interest rate is given by $q=1 / \beta-1$ (which follows from the Euler equation applied to steady state) and the trade deficit, $F_{n}$, is measured in the data. All of the trade data at the country level are obtained from WIOD, while those at the U.S. state level are obtained from the CFS, the FTB, and the authors' calculations.

Terminal NFA, $\mathcal{A}_{n T+1}$, is set to 0 for all regions. Choose $T$ sufficiently large and make use of the turnpike theorem.

Preference weights For each country, the labor wedge, $\zeta_{n}$ is chosen using the optimal labor supply condition:

$$
\frac{H_{n}}{L_{n}}=1-\left(\zeta_{n}\right)^{\phi}\left(\frac{P_{n}^{c} C_{n}}{w_{n} H_{n}}\right)^{\phi}\left(\frac{H_{n}}{L_{n}}\right)^{\phi}
$$


Data are available on consumption expenditures at current prices, $P_{n}^{c} C_{n}=E_{n}^{c}$, at both the country level in WIOD; we assume that consumption expenditure shares in GDP in each U.S. state are equal to the U.S. share. Using data on GDP at current prices, employee compensation is measured as $w_{n} H_{n}=(1-\alpha) G D P_{n}$. Data on both total employment, $H_{n}$, and total population, $L_{n}$, are available ate both the country in PWT and at U.S. state level in BEA. We scale both the employment and population data proportionately across U.S. states so that their respective sums equal the total U.S. values.

Sectoral weights in total consumption and investment are computed at the country and state level directly as

$$
\begin{aligned}
& \omega_{n}^{c j}=\frac{E_{n}^{c j}}{\sum_{j=1}^{J} E_{n}^{c j}}, \\
& \omega_{n}^{x j}=\frac{E_{n}^{x j}}{\sum_{j=1}^{J} E_{n}^{x j}},
\end{aligned}
$$

where $E_{n}^{c j}$ denotes country $n$ 's consumption expenditures in sector $j$ at current prices and $E_{n}^{x j}$ denotes country $n$ 's investment expenditures in sector $j$ at current prices.

Input shares The intermediate input shares include the ratio of value added to gross output, $v_{n}^{j}$ and the intermediate input shares, $m u_{n}^{j k}$. Each of these shares is measured directly from WIOD at the country level. The shares for each U.S. state are set equal to the U.S. values.

Productivity and trade barriers Productivity and trade barriers are not directly observable. Instead, we use the model's structure to guide our measurement. Specifically, we employ a gravity approach as in Levchenko and Zhang (2016). The usual gravity equation that pops out of the Eaton-Kortum model, as well as other work horse models, links bilateral trade shares to comparative advantage forces and trade barriers as follows:

$$
\ln \left(\frac{\operatorname{Tr} d_{n i}^{j}}{\operatorname{Tr} d_{n n}^{j}}\right)=\underbrace{\ln \left(\left(A_{i}^{j}\right)^{\nu_{i}^{j} \theta^{j}}\left(u_{i}^{j}\right)^{-\theta^{j}}\right)}_{S_{i}^{j}}-\underbrace{\ln \left(\left(A_{n}^{j}\right)^{\nu_{n}^{j} \theta^{j}}\left(u_{n}^{j}\right)^{-\theta^{j}}\right)}_{S_{n}^{j}}+\ln \left(\left(d_{n i}^{j}\right)^{-\theta^{j}}\right) .
$$

The term $\operatorname{Tr}_{n i}^{j}$ denotes the value of trade flows in sector $j$ originating in region $i$ destined for region $n$. Therefore, $\operatorname{Trd}_{n i}^{j} / \operatorname{Tr}_{n n}^{j}$ depicts region $i$ 's share in region $n$ 's absorbtion of sector $j$. $S_{n}^{j}$ captures region $n$ 's "relative state of technology", or relative competitiveness, in 
sector $j$ as a convolution of its costs of inputs and its productivity. Any regional differences in relative trade shares that are not accounted for by regional differences is relative states of technology are captured by the bilateral trade barriers. The goal is to isolate each regions level of productivity in each sector. If one had data on bilateral trade frictions, equation (1) can be taken directly to the data to estimate the states of technology. However, bilateral trade barriers at the sector level are unobservable. Instead, the trade barriers are assumed to be parsimoniously described by observable gravity variables as follows:

$$
\ln \left(\left(d_{n i}^{j}\right)^{-\theta^{j}}\right)=e x_{i}^{j}+\sum_{\ell} d i s t_{n i}^{\ell j}+\operatorname{curr}_{n i}^{j}+\operatorname{lang}_{n i}^{j}+\operatorname{state}_{n i}^{j}+\varepsilon_{n i}^{j}
$$

In line with Waugh (2010), the parsimonious specification in equation (2) includes an exporter fixed effect, in addition to standard gravity variables: dummies for distance intervals between the importer and exporter, a dummy for whether the importer and exporters share a common currency, a dummy for whether they share a common official language, and a dummy for whether the two trading partners are both U.S. states (to control for home bias). Distance dummies are computed using six intervals, indexed by $\ell$, based on miles: [0,350), $[350: 750),[750,1500),[1500,3000),[3000,6000),[6000, \infty)$. The residual captures forces that are not explicitly measured, while the usual assumptions about independence apply. Combining equations (1) and (2) yield an estimable gravity equation:

$$
\ln \left(\frac{\operatorname{Tr} d_{n i}^{j}}{\operatorname{Tr} d_{n n}^{j}}\right)=S_{i}^{j}-S_{n}^{j}+\underbrace{e x_{i}^{j}+\sum_{\ell} d i s t_{n i}^{l j}+c u r r_{n i}^{j}+l a n g_{n i}^{j}+s t a t e_{n i}^{j}+\varepsilon_{n i}^{j}}_{\ln \left(\left(d_{n i}^{j}\right)^{-\theta^{j}}\right)}
$$

Many of the bilateral trade flows that are needed to estimate equation (3) are not available. In particular, there is no data, to our knowledge, on bilateral trade flows between U.S. states in agriculture, mining, or any service sectors. In addition, there is no data available on bilateral trade between U.S. states and non-U.S. countries for any of the service sectors. The Appendix describes how we construct sensible estimates for the missing trade flows using all available bilateral trade flows and production in all sectors and all regions as well as gravity variables, such as distance, etc. We employ these estimated trade flows in equation (3) in order to estimate productivity and bilateral trade flows in all sectors for every region.

Equation (3) is estimated using OLS for each sector separately for all regions excluding the rest-of-world aggregate (ROW) since the gravity variables would not make sense. We impute the exporter fixed effect coefficient, $e x_{n}^{j}$, and the states of technology, $S_{n}^{j}$, by regressing the 
respective estimates for all other regions against logged GDP per capita and logged GDP, and then recover the corresponding estimates for ROW using its GDP per capita. Bilateral trade flows that are 0 are omitted. With trade elasticities, $\theta^{j}$, given, the coefficients from the regression make for a straightforward construction of the trade barriers $d_{n i}^{j}$.

The available degrees of freedom imply that, in each sector, the region-specific states of technology, $S_{n}^{j}$, are identified only up to a normalization; we take Australia as the reference country based on alphabetical ordering: $S_{A U S}^{j}=0$ for all sectors $j$. Information on sectorspecific relative productivity levels across regions, $A_{n}^{j}$ is contained in the estimated relative states of technology, $S_{n}^{j}$. Recall that

$$
\begin{aligned}
& S_{n}^{j}=\ln \left(\left(A_{n}^{j}\right)^{\nu_{n}^{j} \theta^{j}}\left(u_{n}^{j}\right)^{-\theta^{j}}\right), \\
& u_{n}^{j}=\left(\frac{r_{n}}{\alpha \nu_{n}^{j}}\right)^{\alpha \nu_{n}^{j}}\left(\frac{w_{n}}{(1-\alpha) \nu_{n}^{j}}\right)^{(1-\alpha) \nu_{n}^{j}} \prod_{k=1}^{J}\left(\frac{P_{n}^{k}}{\mu_{n}^{j k}\left(1-\nu_{n}^{j}\right)}\right)^{\mu_{n}^{j k}\left(1-\nu_{n}^{j}\right)} .
\end{aligned}
$$

Having data on wages, rental rates of capital, and intermediate input prices would allow for a straightforward isolation of $A_{n}^{j}$. Each of these are measured through the lens of the model. Wages are measured as: $w_{n}=(1-\alpha) \frac{G D P_{n}}{H_{n}}$, where $G D P_{n}$ is aggregate value added in current prices in region $n$, and $H_{n}$ is aggregate employment. The rental rate on capital measured as: $r_{n}=\alpha \frac{G D P_{n}}{K_{n}}$, where $K_{n}$ is the aggregate capital stock in region $n$. Lastly, sectoral prices are measured using "trade-based estimates" as in Eaton and Kortum (2002). Estimates from the gravity regression provides information to construct the sectoral prices since the model implies that

$$
\begin{aligned}
P_{n}^{j} & =\gamma^{j}\left[\sum_{i=1}^{N}\left(\left(A_{i}^{j}\right)^{-\nu_{i}^{j}} u_{i}^{j} d_{n i}^{j}\right)^{-\theta^{j}}\right]^{-1 / \theta^{j}} \\
& =\gamma^{j}\left[\sum_{i=1}^{N} \exp \left(S_{i}^{j}\right)\left(d_{n i}^{j}\right)^{-\theta^{j}}\right]^{-1 / \theta^{j}}
\end{aligned}
$$

The term $\gamma^{j}=\Gamma\left(1+\frac{1}{\theta^{j}}(1-\eta)\right)^{1 /(1-\eta)}$, where $\Gamma(\cdot)$ is the Gamma function. Simply input the estimated bilateral trade barriers and the estimated states of technology to construct the sectoral prices. Having measured wages, rental rates, and prices on sectoral inputs, one can peel off the units cost component, $u_{n}^{j}$, from the estimated state of technology, $S_{n}^{j}$, to infer the productivity, $A_{n}^{j}$. 


\section{Results}

\subsection{U.S. import tariff on Mexico}

We examine the effect of a one-time, permanent increase in trade barriers between the United States and Mexico. In particular, we consider $20 \%$ tariff on all goods and services shipped directly from Mexico. We assume that Mexico retaliates immediately by imposing an equal tariff on all goods shipped from the United States. For parsimony, we abstract from complications stemming from rules of origin, so the tariffs are applied on all bilateral trade flows between the two countries. Let $\tilde{d}_{n i}^{j}$ denote the trade barrier of shipping goods from region $i$ to region $n$ in sector $j$. We set $\tilde{d}_{n i}^{j}=d_{n i}^{j}+0.2$ if $n$ is a U.S. state and $i$ is Mexico, or if $n$ is Mexico and $i$ is a U.S. state. All other parameters are held fixed at their calibrated levels, including the trade barriers between U.S. states.

\section{Conclusion}

TBD 


\section{References}

Alvarez, Fernando and Robert E. Lucas. 2007. "General Equilibrium Analysis of the EatonKortum Model of International Trade." Journal of Monetary Economics 54 (6):1726-1768.

Caliendo, Lorenzo and Fernando Parro. 2015. "Estimates of the Trade and Welfare Effects of NAFTA." Review of Economic Studies 82 (1):1-44.

Eaton, Jonathan and Samuel Kortum. 2002. "Technology, Geography, and Trade." Econometrica 70 (5):1741-1779.

Eaton, Jonathan, Samuel Kortum, Brent Neiman, and John Romalis. 2016. "Trade and the Global Recession." American Economic Review 106 (11):3401-3438.

Feenstra, Robert C., Robert Inklaar, and Marcel Timmer. 2015. "The Next Generation of the Penn World Table." American Economic Review 105 (10):3150-82.

Gollin, Douglas. 2002. "Getting Income Shares Right." Journal of Political Economy $110(2): 458-474$.

Levchenko, Andrei and Jing Zhang. 2016. "The Evolution of Comparative Advantage: Measurement and Welfare Implications,." Journal of Monetary Economics 78:96-111.

Peterman, William B. 2016. "Reconciling Micro And Macro Estimates Of The Frisch Labor Supply Elasticity." Economic Inquiry 54 (1):100-120.

Sposi, Michael. 2016. "Evolving Comparative Advantage, Sectoral Linkages, and Structural Change." Mimeo, Federal Reserve Bank of Dallas.

Timmer, Marcel P., Erik Dietzenbacher, Bart Los, Robert Stehrer, and Gaaitzen J. de Vries. 2015. "An Illustrated Guide to the World Input-Output Database: The Case of Global Automotive Production." Review of International Economics 23 (3):575-605.

Timmer, Marcel P., Bart Los, Robert Stehrer, and Gaaitzen J. de Vries. 2016. "An Anatomy of the Global Trade Slowdown based on the WIOD 2016 Release." GGDC research memorandum 162, Groningen Growth and Development Center.

Waugh, Michael E. 2010. "International Trade and Income Differences." American Economic Review 22 (5):2093-2124. 


\section{A Data}

The primary data sources include Bureau of Economic Analysis Regional Economic Accounts (BEA), Census Bureau Commodity Flow Survey (CFS), Census Bureau Foreign Trade Database (FTB), version 9.0 of the Penn World Table (Feenstra, Inklaar, and Timmer, 2015 , (PWT)), World Input-Output Database (Timmer, Dietzenbacher, Los, Stehrer, and de Vries, 2015; Timmer, Los, Stehrer, and de Vries, 2016. (WIOD)), and Centre d'Etudes Prospectives et d'Informations Internationales (CEPII).

Sector classification...

Our data include 91 regions: 50 U.S. states, 40 non-U.S. countries, and a rest-of world aggregate.

We moved Luxembourg and Malta into ROW due to oddities in the disaggregate data from WIOD. We also exclude the United States as a country since we include all 50 U.S. states.

\section{A.1 National accounts}

Population and employment at the country level come from the PWT. U.S. state level population and employment from BEA. The state-level population and employment numbers are scaled proportionately across states so that sum of U.S. state-level data match the U.S. level in PWT.

\section{A.2 Production}

BEA for state-level value added in each sector. Convert to gross output by assuming the the share of value added in gross output in each U.S. state is the same as the ratio for the U.S. as a whole. The share for the U.S. as a whole is obtained from WIOD. Sector-specific ratios are used.

Gross output is obtained from WIOD using value added plus intermediate expenditures. This leaves out other distortional margins including ...

\section{A.3 Bilateral trade}

Bilateral trade data across countries for every sector are taken from WIOD.

Bilateral trade between U.S. states and non-U.S. countries is taken from Census. These data are available available for agriculture, mining, and all 8 manufacturing sectors. For each of these sectors, we scale the trade flows proportionately across states so that (i) the sum of all states exports to any non-U.S. country equals the value for U.S. exports to that country obtained from WIOD and (ii) the sum of all states imports from any non-U.S. country equals the value for U.S. imports from that country obtained from WIOD.

Bilateral trade between U.S. states is obtained from CFS. These data are based on survey of ?? commodities flows between ?? U.S. cities. We aggregate these commodity groups into our 8 manufacturing sectors and assign each city to 1 U.S. state to obtain bilateral trade 
flows between states. We then scale these flows so that each state's gross output is accounted for by sales to non-U.S. countries as well as sales to all U.S. states. More specifically, let $\left(n_{s}, i_{s}\right)$ denote arbitrary U.S. states, let $n_{f}$ denote an arbitrary non-U.S. country, and $j$ be an arbitrary sector. We use the following condition:

$$
G O_{i_{s}}^{j}=\underbrace{\sum_{n_{f} \in\{\text { non-U.S. }\}} \operatorname{Trd}_{n_{f} i_{s}}^{j}}_{\text {Sales to non-U.S. }}+\underbrace{\sum_{n_{s} \in\{\text { U.S. states }\}} \operatorname{Trd} d_{n_{s}, i_{s}}^{j},}_{\text {Sales to U.S. states }}
$$

which says that sectoral output in a given state must equal the sum of that states sales to all locations (including itself). This condition will not hold for the raw data beacuse of at least two reasons: (i) combining different data sources, (ii) CFS is based on a survey. Therefore, we scale state $i_{s}$ 's sales to all U.S. states- $T r d_{n_{s} i_{s}}^{j}, n_{s} \in\{$ U.S. state $\}$ (including to itself), proportionately, so that equation (A.1) holds. There are 4 cases worth mentioning for which gross output minus exports to foreign countries is negative: Louisiana-agriculture, Alaskaagriculture, Delaware-mining, and Hawaii-machinery and equipment. We believe that the state-level gross output data is more accurately measured than that state-level export data. As such, in these cases we adjust the state's exports to all foreign countries proportionately so that it sums to equal exactly that state's gross output.

Inferring missing bilateral trade flows There are no bilateral trade data available for the following: U.S. states with foreign countries in service sectors; U.S. states with other U.S. states for agriculture, mining, and service sectors. This information is needed to employ the gravity specification to estimate sectoral productivity in each region as well as the sectoral bilateral trade barriers between each region. For this purpose, we impute the missing data.

First, we impute missing bilateral trade flows between U.S. states and non-U.S. countries for each of the 10 service sectors

- $M_{n}$ : Region-importer fixed effect

- $E_{i}$ : Region-exporter fixed effect

- $S_{j}$ : Sector fixed effect

- $\sum_{n_{s} \in \text { U.S. }} \operatorname{Tr}_{n_{s}, i}^{j}$ : U.S. imports from that country $i$ in sector $j$.

- $\mathbb{I}_{n \in \mathrm{U} . \mathrm{S}}$ : Dummy for if importer is a U.S. state

- $\sum_{i_{s} \in \mathrm{U} . \mathrm{S} .} \operatorname{Trd}_{n, i_{s}}^{j}$ :Interaction: U.S. exports to country $n$ in sector $j$.

- $\mathbb{I}_{i \in \mathrm{U} . \mathrm{S}}$ : Dummy for if exporter is a U.S. state

- dist $_{n i}$ : Distance in miles measured using great circle method based on latitude and longitude coordinates of largest city in the region. 
- $\mathbb{I}_{n=i}$ : Dummy for whether importer is same as exporter

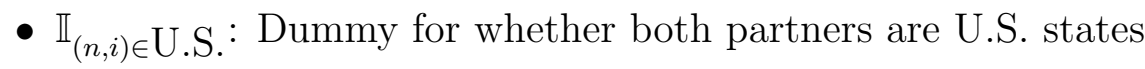

- $\operatorname{curr}_{n i}$ Dummy for whether the two regions share a common currency

- $\operatorname{lang}_{n i}$ : Dummy for whether the two regions share a common official language

As before, for each of the service sectors, we scale the trade flows proportionately across states so that (i) the sum of all states exports to any non-U.S. country equals the value for U.S. exports to that country obtained from WIOD and (ii) the sum of all states imports from any non-U.S. country equals the value for U.S. imports from that country obtained from WIOD.

Second, we impute missing bilateral trade flows between U.S. states for agriculture, mining, and each of the 10 service sectors. For each of these sectors we scale the state-to-state bilateral trade, proportionately, so that equation (A.1) holds for each state.

\section{B Equilibrium conditions}

Household optimization The problem can be broken down into two steps. First, solve for the intratemporal decision problem for the household, which entails choosing sectoral consumption and investment, taking total consumption and investment spending as given. That is, for sectoral consumption,

$$
\begin{aligned}
& \max _{C_{n t}^{j}} \prod_{j=1}^{J}\left(C_{n t}^{j}\right)^{\omega_{n}^{c j}} \\
& \text { s.t. } \sum_{j=1}^{J}\left(P_{n t}^{j} C_{n t}^{j}\right)=E_{n t}^{c},
\end{aligned}
$$

where $E_{c n t}$ denotes total consumption expenditures in country $n$ at time $t$. The problem for choosing sectoral investment is analogous. The solution is given by

$$
C_{n t}^{j}=\omega_{n}^{c j}\left(\frac{E_{n t}^{c}}{P_{n t}^{j}}\right), \quad X_{n t}^{j}=\omega_{n}^{x j}\left(\frac{E_{n t}^{x}}{P_{n t}^{j}}\right) .
$$

Define ideal price indices for consumption and investment as

$$
P_{n t}^{c}=\prod_{j=1}^{J}\left(\frac{P_{n t}^{j}}{\omega_{n}^{c j}}\right)^{\omega_{n}^{c j}}, \quad P_{n t}^{x}=\prod_{j=1}^{J}\left(\frac{P_{n t}^{j}}{\omega_{n}^{x j}}\right)^{\omega_{n}^{x j}} .
$$

Then $E_{n t}^{c}=P_{n t}^{c} C_{n t}=\sum_{j=1}^{J}\left(P_{n t}^{j} C_{n t}^{j}\right)$ and $E_{n t=}^{x} P_{n t}^{x} X_{n t}=\sum_{j=1}^{J}\left(P_{n t}^{j} X_{n t}^{j}\right)$. 
Second, solve for the intertemporal decision problem of the household, which entails choosing optimal paths of total consumption, total investment, net purchases of bonds, and labor supply. For convenience, rearrange the capital accumulation equation so that

$$
X_{n t}=\Phi\left(K_{n t+1}, K_{n t}\right)=\left(\frac{1}{\chi}\right)^{\frac{1}{\lambda}}\left(K_{n t+1}-(1-\delta) K_{n t}\right)^{\frac{1}{\lambda}} K_{n t}^{\frac{\lambda-1}{\lambda}} .
$$

The dynamic optimization problem for the household in region $n$ is the following:

$$
\begin{aligned}
\max _{\substack{\left\{C_{n t}, X_{n t}, B_{n t}, H_{n t}, K_{n t+1}, \mathcal{A}_{n t+1}\right\}_{t=1}^{T}}} & \sum_{t=1}^{T} \beta^{t-1} L_{n}\left[\ln \left(\frac{C_{n t}}{L_{n}}\right)+\frac{\left(1-\frac{H_{n t}}{L_{n}}\right)^{1-1 / \phi}}{1-1 / \phi}\right] \\
\text { s.t. } & P_{n t}^{c} C_{n t}+P_{n t}^{x} \Phi\left(K_{i t+1}, K_{i t}\right)+B_{n t}=r_{n t} K_{n t}+w_{n t} H_{n t}+q_{t} \mathcal{A}_{n t}, \forall t, \\
& \Phi\left(K_{n t+1}, K_{n t}\right)=\left(\frac{1}{\chi}\right)^{\frac{1}{\lambda}}\left(K_{n t+1}-(1-\delta) K_{n t}\right)^{\frac{1}{\lambda}} K_{n t}^{\frac{\lambda-1}{\lambda}}, \forall t \\
& \mathcal{A}_{n t+1}=\mathcal{A}_{n t}+B_{n t}, \forall t \\
& H_{n t} \in\left[0, L_{n}\right], \forall t \\
& K_{n 1}, \mathcal{A}_{n 1}, \mathcal{A}_{n T+1} \text { given. }
\end{aligned}
$$

The optimal paths for consumption, investment, and net purchases of bonds are chosen so that the two following intertemporal Euler equations are satisfied:

$$
\begin{aligned}
\frac{C_{n t+1}}{C_{n t}} & =\beta\left(\frac{1+q_{t+1}}{P_{n t+1}^{c} / P_{n t}^{c}}\right), \\
\frac{C_{n t+1}}{C_{n t}} & =\beta\left(\frac{\frac{r_{n t+1}}{P_{n t+1}^{x}}-\Phi_{2}\left(K_{n t+2}, K_{n t+1}\right)}{\Phi_{1}\left(K_{n t+1}, K_{n t}\right)}\right)\left(\frac{P_{n t+1}^{x} / P_{n t+1}^{c}}{P_{n t}^{x} / P_{n t}^{c}}\right),
\end{aligned}
$$

where $\Phi_{1}(\cdot, \cdot)$ and $\Phi_{2}(\cdot, \cdot)$ denote the first derivatives of the adjustment-cost function with respect to the first and second arguments, respectively:

$$
\begin{aligned}
& \Phi_{1}\left(K^{\prime}, K\right)=\left(\frac{1}{\chi}\right)^{\frac{1}{\lambda}}\left(\frac{1}{\lambda}\right)\left(\frac{K^{\prime}}{K}-(1-\delta)\right)^{\frac{1-\lambda}{\lambda}} \\
& \Phi_{2}\left(K^{\prime}, K\right)=\left(\frac{1}{\chi}\right)^{\frac{1}{\lambda}}\left(\frac{1}{\lambda}\right)\left(\frac{K^{\prime}}{K}-(1-\delta)\right)^{\frac{1-\lambda}{\lambda}}\left((\lambda-1) \frac{K^{\prime}}{K}-\lambda(1-\delta)\right) .
\end{aligned}
$$

The optimal labor supply decision is determined by:

$$
\frac{H_{n t}}{L_{n}}=1-\left(\zeta_{n}\right)^{\phi}\left(\frac{P_{n t}^{c} C_{n t}}{w_{n t} L_{n}}\right)^{\phi}
$$


Firm optimization From now on each variety in sector $j$ is denoted by its vector of idiosyncratic productivity draws $z^{j}=\left(z_{1}^{j}, z_{2}^{j}, \ldots, z_{I}^{j}\right)^{\prime}$ as in Alvarez and Lucas (2007). Markets are perfectly competitive, so firms set prices equal to marginal costs. Denote the price of variety $z^{j}$, produced in country $i$ and purchased by country $n$, as $p_{n i}^{j}\left(z^{j}\right)$. Then $p_{n i}^{j}\left(z^{j}\right)=p_{i i}^{j}\left(z^{j}\right) d_{n i}^{j}$, where $p_{i i}^{j}\left(z^{j}\right)$ is the marginal cost of producing variety $z^{j}$ in country $i$. Since country $n$ purchases each variety from the country that can deliver it at the lowest price, the price in country $n$ is $p_{n}^{j}\left(z^{j}\right)=\min _{i=1, \ldots, N}\left[p_{i i}^{j}\left(z^{j}\right) d_{n i}^{j}\right]$. Using the fact that idiosyncratic productivity draws are distributed Fréchet, the price of the sector $j$ composite good in country $n$ is

$$
P_{n t}^{j}=\gamma_{j}\left[\sum_{i=1}^{N}\left(\left(A_{i}^{j}\right)^{-\nu_{i}^{j}} u_{i t}^{j} d_{n i}^{j}\right)^{-\theta^{j}}\right]^{-\frac{1}{\theta^{j}}},
$$

where $u_{i t}^{j}=\left(\frac{r_{i t}}{\alpha \nu_{i}^{j}}\right)^{\alpha \nu_{i}^{j}}\left(\frac{w_{i t}}{(1-\alpha) \nu_{i}^{j}}\right)^{(1-\alpha) \nu_{i}^{j}} \prod_{k=1}^{J}\left(\frac{P_{i t}^{k}}{\mu_{i}^{j k}\left(1-\nu_{i}^{j}\right)}\right)^{\mu_{i}^{j k}\left(1-\nu_{i}^{j}\right)}$ is the unit cost for a bundle of

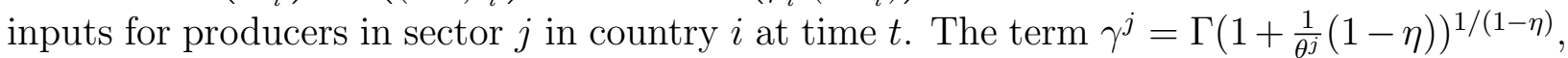
where $\Gamma(\cdot)$ is the Gamma function.

Define total factor usage in sector $j$ by aggregating up across the individual varieties.

$$
\begin{aligned}
K_{n t}^{j} & =\int K_{n t}^{j}\left(z^{j}\right) \varphi\left(z^{j}\right) d z^{j}, & H_{n t}^{j} & =\int H_{n t}^{j}\left(z^{j}\right) \varphi\left(z^{j}\right) d z^{j}, \\
M_{n t}^{j k} & =\int M_{n t}^{j k}\left(z^{j}\right) \varphi\left(z^{j}\right) d z^{j}, & Y_{n t}^{j} & =\int Y_{n t}^{j}\left(z^{j}\right) \varphi\left(z^{j}\right) d z^{j},
\end{aligned}
$$

where $\varphi=\prod_{n} \varphi_{n}$ is the joint density for idiosyncratic productivity draws across countries ( $\varphi_{n}$ is country $n$ 's density function). The term $K_{n t}^{j}\left(z^{j}\right)$ denotes the quantity of capital stock used in the production of variety $z^{j}$ at time $t$. If country $i$ imports variety $z^{j}$, then $K_{n t}^{j}\left(z^{j}\right)=0$. Hence, $K_{n t}^{j}$ is the total quantity of capital stock used in sector $j$ in country $n$ at time $t$. Similarly, $H_{n t}^{j}$ is the quantity of labor hours used in sector $j$ in country $n$ at time $t$. $M_{n t}^{j k}$ denotes the quantity of composite good $k$ that country $n$ uses as an intermediate input in production in sector $j$ at time $t . Y_{n t}^{j}$ is the quantity of the sector $j$ output produced by country $n$ at time $t$.

At the firm level, factor expenses exhaust the value of output, which implies:

$$
\begin{aligned}
r_{n t} K_{n t}^{j} & =\alpha \nu_{n}^{j} P_{n t}^{j} Y_{n t}^{j}, \\
w_{n t} H_{n t}^{j} & =(1-\alpha) \nu_{n}^{j} P_{n t}^{j} Y_{n t}^{j}, \\
P_{n t}^{k} M_{n t}^{j k} & =\left(1-\nu_{n}^{j}\right) \mu_{n}^{j k} P_{n t}^{j} Y_{n t}^{j} .
\end{aligned}
$$


Trade flows In sector $j$, the fraction of country $n$ 's expenditures allocated to varieties produced by country $i$ at time $t$ is given by

$$
\pi_{n i t}^{j}=\frac{\left(\left(A_{n}^{j}\right)^{-\nu_{n}^{j}} u_{n t}^{j} d_{n i}^{j}\right)^{-\theta^{j}}}{\sum_{i=1}^{N}\left(\left(A_{i}^{j}\right)^{-\nu_{i}^{j}} u_{i t}^{j} d_{n i}^{j}\right)^{-\theta^{j}}}
$$

Market clearing conditions Within each country markets must clear:

$$
\begin{gathered}
\sum_{j=1}^{J} K_{n t}^{j}=K_{n t}, \\
\sum_{j=1}^{J} H_{n t}^{j}=H_{n t}, \\
C_{n t}^{j}+X_{n t}^{j}+\sum_{k=1}^{J} M_{i t}^{k j}=Q_{n t}^{j}, \text { for each } j=1, \ldots, J .
\end{gathered}
$$

The first two conditions impose that the capital and labor markets clear in country $n$. The second condition requires that the use of composite good $j$ equal its supply. Its use consists of consumption by the representative household and intermediate use by domestic firms. Its supply is the quantity of the composite good, consisting of both domestically- and foreignproduced varieties.

The next conditions require that the value of sector $j$ output produced by country $n$ is equal to the value of sector $j$ goods that all countries purchase from country $n$ :

$$
P_{n t}^{j} Y_{n t}^{j}=\sum_{i=1}^{N}\left(P_{i t}^{j} C_{i t}^{j}+\sum_{k=1}^{J} P_{i t}^{j} M_{i t}^{k j}\right) \pi_{i n t}^{j} .
$$

Finally, the aggregate resource constraint must hold in each country: the current account equals net exports plus net-foreign income:

$$
B_{n t}=\sum_{j=1}^{J}\left[P_{n t}^{j} Y_{n t}^{j}-\left(P_{n t}^{j} C_{n t}^{j}+\sum_{k=1}^{J} P_{n t}^{j} M_{n t}^{k j}\right)\right]+q_{t} \mathcal{A}_{i t}
$$

where the term inside the square brackets is country $n$ 's net exports in sector $j$ at time $t$ (gross output minus gross absorption). This condition, combined with the other market clearing conditions above, implies the more familiar condition that $Y=C+I+N X$ (with a heavy abuse of notation). In addition, these conditions imply that the world market for one-period bonds clears: $\sum_{n=1}^{N} B_{n t}=0$. 